\title{
EXTRACTO DEL DICTAMEN DEL CONSEJO DE ESTADO SOBRE EL ESTATUTO DE ROMA QUE INSTITUYE LA CORTE PENAL INTERNACIONAL
}

La Comisión Permanente del Consejo de Estado, en sesión celebrada el día 22 de julio de 1999, con asistencia de los señores que al margen se expresan (señores: Cavero Lataillade, Presidente, Lavilla Alsina; Arozamena Sierra; de Mateo Lage; Sánchez del Corral y del Río; Manzanares Samaniego; Vizcaíno Márquez; Pérez-Tenessa Hernández; Martín Oviedo, Secretario General.), emitió, por unanimidad, el siguiente dictamen:

"En cumplimiento de la Orden de V.E. de 22 de abril de 1999, con registro de entrada el día 28 siguiente, el Consejo de Estado ha examinado el expediente relativo al Estatuto de Roma que instituye la Corte Penal Internacional, hecho en Roma el 17 de julio de 1998.

De antecedentes resulta:

Primero.- El Estatuto de Roma de la Corte Penal Internacional está compuesto por 128 artículos, agrupados sistemáticamente en trece partes. (...).

(...) La parte III del Estatuto (arts. 22 a 23) proclama y desarrolla, como principios generales del Derecho Penal con arreglo a los que actuará la Corte, los siguientes: nullum crimen sine lege, nulla poena sine lege, irretroactividad ratione personae, responsabilidad penal individual, exclusión de los menores de 18 años de la competencia de la Corte, improcedencia de distinción basada en el cargo oficial, responsabilidad de los jefes y otros superiores, imprescriptibilidad de los crímenes, requerimientos de que haya intencionalidad y conocimiento de los elementos materiales del crimen, apreciación de circunstancias eximentes de responsabilidad penal con expresa inclusión del error de hecho y posible inclusión o exclusión del error de derecho y del cumplimiento de órdenes superiores y disposiciones legales (...). 
(...) Segundo-- Figura en el expediente instruido en relación con el Estatuto reseñado un informe del Ministerio de Justicia, acompañado de una "nota singular sobre la inmunidad del Rey" (ambos de 23 de febrero de 1999) (...).

(...) En la "nota sobre la inviolabilidad del Rey en relación al Estatuto de la Corte Penal Internacional" se alcanza las siguientes conclusiones:

1. La responsabilidad de los Jefes de Estado por violaciones del Derecho Internacional es un principio de derecho internacional.

2. Las normas sobre inmunidad de los Jefes de Estado, en tales hipótesis, no son extrapolables al plano internacional.

3. La Constitución no ha regulado, ni podía regular, la proyección internacional del principio interno de inviolabilidad.

4. Aceptado el principio abstracto de la responsabilidad de los Jefes de Estado, deben entrar en juego los principios internos a efectos de determinar la responsabilidad penal individual, en función de la imputabilidad de los actos internos de adopción de los actos regios, de manera que, si constitucionalmente el Jefe del Estado no puede tomar decisiones autónomas, la responsabilidad penal se desplaza al refrendante.

5. No se advierte oposición irreductible entre la Constitución y el Estatuto de la Corte y, en consecuencia, no necesita ser modificada aquélla.

Tercero.- Obra asimismo en el expediente un informe sobre el Estatuto de la Corte Penal Internacional elaborado el 17 de febrero de 1999 por la Asesoría Jurídica General del Ministerio de Defensa (y transmitido al Ministerio de Asuntos Exteriores el 26 de marzo siguiente).

Dicho informe se desglosa en cinco apartados, a saber:

1. Consideraciones previas, con exposición de antecedentes y observaciones sobre la incidencia del Estado en el ordenamiento español. Entre ellas pueden destacarse las siguientes:

- Dado el principio de complementariedad sobre el que se asienta la competencia de la Corte, el Estatuto no viene a derogar ni a sustituir el ejercicio de la potestad jurisdiccional soberana del Estado que el artículo 117.3 de la Constitución atribuye exclusivamente a los Juzgados y Tribunales determinados por las leyes. «En todo caso, cualquier posible obstáculo para la ratificación del Estatuto quedaría salvado acudiendo al procedimiento previsto en el artículo 93 de la Constitución, que permite atribuir a una organización o institución internacional el ejercicio de competencias derivadas de la propia Constitución, si bien en este caso la autorización de las Cortes debe expresarse mediante Ley Orgánica".

- Aunque ello no sea condición previa para la ratificación del Estatuto por España, convendría ir preparando los estudios necesarios para introducir en el Libro Segundo del Código Penal la incriminación autónoma de los llamados "crímenes de lesa humanidad" con vista a que, en un hipotético caso de inicio de una investigación por el Fiscal de la Corte Penal Internacional por esta clase de delitos presuntamente cometidos en nuestro territorio, quede fuera de toda duda el derecho de España a ejercer jurisdicción con respecto a los mismos (...). 
(...) - Respecto de la "improcedencia del cargo oficial" regulada en el artículo 27 del Estatuto, no se aprecia antinomia insalvable con el artículo 56.3 de la Constitución, proponiendo que España, al ratificar el Estatuto, formule una declaración interpretativa del siguiente tenor: "El Gobierno del Reino de España entiende que la disposición contenida en el párrafo segundo del artículo 27 del Estatuto, según la cual las inmunidades y las normas de procedimiento especiales que conlleve el cargo oficial de una persona, con arreglo al derecho interno o al derecho internacional, no obstarán para que la Corte ejerza su competencia sobre ella, resulta aplicable en relación con los actos de que dicha persona sea responsable". No siendo el Rey responsable de sus actos, que están siempre sujetos a refrendo, tal vez por esta vía pudiera salvarse el problema constitucional apuntado (...).

(...) - La previsión relativa a la pena de reclusión perpetua en el artículo 77 del Estatuto, incompatible en principio con el artículo 25.2 de la Constitución, no constituye causa optativa para su ratificación por España gracias a lo dispuesto en el artículo 80 y las posibilidades de reducción de la pena ex artículo 110.4 que se remite a "otros factores indicados en las Reglas de Procedimiento y Prueba que permitan determinar un cambio en las circunstancias" (pudiendo encontrar cabida entre ellos nuestros criterios constitucionales de reeducación y reinserción social) (...).

(...) 2. Declaraciones interpretativas.

Se reitera lo antes expuesto en relación a la que se podría formular respecto del artículo $27 \mathrm{y}$, en todo caso, se estima que de no efectuarla se podría sostener que eel tratamiento competencial y funcional de la Corona en la legislación española permitiría, desde un punto de vista técnico-jurídico y doctrinal, mantener su inmunidad, situación ésta que no se produciría en los casos de otras Jefaturas de Estado, precisamente por el tratamiento constitucional de su esfera competencial, funcional y de decisión" (...)

(...) Cuarto-- El Gabinete de Tratados de la Secretaría General Técnica del Ministerio de Asuntos Exteriores ha elaborado el 22 de abril de 1999 informe con propuesta de resolución sobre el Estatuto de Roma que instituye la Corte Penal Internacional (...).

(...) Respecto al trámite parlamentario que debe seguir este Estatuto, el Ministerio de Asuntos Exteriores opina que la autorización de las Cortes Generales es necesaria según lo dispuesto en el artículo 93 de la Constitución, que exige Ley Orgánica para que las Cortes puedan autorizar "la celebración de Tratados por los que se atribuya a una organización o institución internacional el ejercicio de competencias derivadas de la Constitución.

A su juicio, el Estatuto de Roma contiene al menos dos normas que suponen la transferencia de competencias derivadas de la Constitución al órgano jurisdiccional creado en el ordenamiento internacional, sustrayéndolas así a los ajuzgados y tribunales determinados por las Leyes", integrantes del Poder Judicial español (art. 117.3 de la Constitución).

En primer lugar, observa que, si bien el artículo 1 del Estatuto de la Corte precisa que ésta tendrá carácter complementario de las jurisdicciones penales 
nacionales, la aplicación de los preceptos dedicados a las condiciones para el ejercicio de la competencia puede determinar que la Corte asuma jurisdicción en casos en que ésta sea concurrente con los órganos nacionales si éstos no están dispuestos a proceder o no pueden hacerlo (art. 17.1), a pesar de las posibles impugnaciones previstas por el artículo 19 y una vez resuelta la cuestión de admisibilidad por la Sala de Apelaciones de acuerdo con lo previsto por el artículo 82.1.a. Ello constituiría una excepción a lo previsto en el artículo 117.3 de la Constitución.

Por otro lado, el Gabinete de Tratados se fija èn que el Estatuto también prevé en su artículo 99.4 la realización de los actos de "asistencia" contenidos en los artículos 93 y 96 directamente por el Fiscal de la Corte "sin la presencia de las autoridades del Estado Parte requerido". Estas actuaciones suponen asismismo, a su parecer, una excepción a la exclusividad del ejercicio de la función judicial prevista por el citado artículo 117.3 de la Constitución, en la medida en que podrían coincidir con funciones judiciales de instrucción, o bien directamente con la misión del Ministerio Fiscal a fin de promover la acción de la justicia en defensa de la legalidad" (art. 124.1 de la Constitución) (...).

(...) Y, en tal estado expediente, el Consejo de Estado emite la presente consulta $(\ldots)$.

(...) III. El Estatuto de Roma que instituye la Corte Penal Internacional ha sido remitido por V.E. al Consejo de Estado de conformidad con lo dispuesto en el artículo 22.1 de la Ley Orgánica del Consejo de Estado, de 22 de abril de 1980, que prescribe la consulta a su Comisión Permanente "en todos los tratados o convenios internacionales sobre la necesidad de autorización de las Cortes Generales con carácter previo a la prestación del consentimiento del Estado".

El tenor de esta competencia entronca en principio, literalmente y de modo primario, con la función de calificación de los tratados internacionales a los efectos de determinar el procedimiento que haya de observarse en el plano interno para su conclusión, de entre los previstos en los artículos 93 y 94.1 y 2 de la Constitución. Superando sin embargo una concepción excesivamente estrecha y a todas luces insuficiente de dicha función, el Consejo de Estado ha venido entendiendo que su competencia en materia de tratados internacionales comprende, siempre que la naturaleza del asunto lo demande, el examen de una eventual aplicación de lo previsto en el artículo 95 de la Constitución que pudiera cerrar -de modo condicional pero inmediato- las vías previstas en los artículos 93 y 94 para la prestación del consentimiento del Estado.

Como quiera que el Consejo de Estado en el ejercicio de la función consultiva vela por la observancia de la Constitución (art. 2.1 de su Ley Orgánica), el asesoramiento completo al Gobierno ha de incluir en tales casos las reflexiones que, aun excediendo de las estrictamente necesarias para la clasificación del tratado a los efectos de los artículos 93 y 94, versen sobre las eventuales obligaciones constitucionales previas a la autorización por las Cortes Generales del tratado. El Consejo de Estado es consciente de que las cuestiones examinadas son susceptibles de otros tratamientos distintos y hasta con puntos de partida divergentes; también 
lo es de que el artículo 95 no constituye per se un procedimiento para la autorización de tratados internacionales si bien, en tanto puede condicionar la válida formación de la voluntad del Estado, aunque éstas no lleven a formular otro pronunciamiento final que el contenido en la conclusión propia del dictamen preceptivo que le ha sido solicitado.

IV. Ya ha sido puesto de relieve que el Estatuto de Roma de la CPI quiere significar un hito de referencia en la institucionalización de la comunidad internacional y que, no obstante su carácter complementario respecto de las jurisdicciones nacionales, implica en última instancia la cesión -siempre que concurran las circunstancias que preve- de determinadas potestades y funciones actualmente ligadas a la soberanía de los Estados, para cuyo ejercicio quedará habilitada la nueva Institución internacional.

La primera reflexión que procede realizar al respecto es la constatación de la posición de principio del constituyente español abierta a la influencia del Derecho internacional, ordenamiento por lo demás de naturaleza intrínsecamente evolutiva. Tal designio es claro en el texto de 1978 y tiene plurales manifestaciones. El preámbulo de la Constitución proclama la voluntad de la Nación española de "colaborar en el fortalecimiento de unas relaciones pacíficas y de eficaz cooperación entre todos los pueblos de la Tierra". Más adelante, el artículo 10.2 prescribe la interpretación de las normas sobre derechos fundamentales y libertades que la Constitución reconoce de conformidad con la Declaración Universal de Derechios Humanos y los tratados y acuerdos internacionales sobre las mismas materias ratificados por España. La orientación internacionalista de la Constitución -como recordaba el dictamen 421/92- alcanza su máxima intensidad en su artículo 93, en cuanto declara que "mediante ley orgánica se podrá autorizar la celebración de tratados por los que se atribuya a una organización o institución internacional el ejercicio de competencias derivadas de la Constitución". Con este precepto el legislador constitucional parecía atender primariamente a la eventual adhesión de España a las Comunidades Europeas pero, como observaba el propio dictamen, dicho artículo no agotó su virtualidad con tal adhesión.

Sin embargo, el artículo 93 tiene límites y no permite romper en todo caso la rigidez propia de los mecanismos de revisión constitucional. Dijo el Tribunal Constitucional en su declaración de 1 de julio de 1992 que el artículo 93 de la Constitución no se prestaría "a ser empleado como instrumento para contrariar o rectificar mandatos o prohibiciones contenidos en la Norma fundamental, pues ni tal precepto es cauce legítimo para la reforma implicita o tácita constitucional ni podría ser llamada atribución de competencias, en coherencia con ello, una tal contradicción, a través del Tratado, de los imperativos constitucionales". "En virtud del artículo 93 las Cortes Generales pueden, en suma, ceder o atribuir el ejercicio de competencias derivadas de la Constitución, no disponer de la Constitución misma, contrariando o permitiendo contrariar sus determinaciones, pues ni el poder de revisión constitucional es una competencia cuyo ejercicio fuera susceptible de cesión ni la propia Constitución admite ser reformada por otro cauce que no sea el de su Título Xn. 
El Estatuto de Roma de la CPI sin duda goza de un acomodo general en los propósitos ínsitos en la Constitución en cuanto a las relaciones exteriores de España y su papel en la comunidad internacional. La declaración antes citada del preámbulo constitucional presenta una evidente comunidad de intereses con las formulaciones expositivas del Estatuto. El reconocimiento de este hecho, sin embargo, no evita que algunas concretas previsiones del Estatuto sean de naturaleza tal que requieran plantearse su compatibilidad con determinados enunciados constitucionales.

En particular, si bien una posición activa de España como Estado que coopera efectivamente (por ejemplo en materia de ejecución de penas) con la Corte en la realización de sus fines no crea mayores problemas, no cabe ignorar que, en el desenvolvimiento de la plenitud de los efectos del Estatuto, podría darse el caso de que el ejercicio por la CPI de su jurisdicción sobre personas sometidas a la jurisdicción española entrara en colisión con prescripciones de la Constitución española, sin que ésta fuera superable por la vía del trasvase del ejercicio de competencias previsto en el artículo 93 del texto constitucional. Aunque tal hipótesis pudiera parecer remota desde el modelo constitucional vigente, no resulta sin embargo excluida en términos de principio, de modo que el análisis de su admisibilidad dentro de la Constitución vigente requiere razonar y abordar la cuestión, no en función de su probabilidad, sino en tanto que real posibilidad si se ratifica el Tratado de referencia.

Así se lo han planteado diversos paises del entorno español, que han considerado -con las singularidades propias de cada caso- la necesidad de revisar sus Constituciones para dar cabida en sus respectivos ordenamientos jurídicos al Estatuto de Roma de la CPI. Sumamente ilustrativa y útil resulta en este sentido, sobre todo para la identificación de ciertas cuestiones a analizar, la toma en consideración de la decisión del Consejo Constitucional francés de 22 de enero de 1999 -y la reforma constitucional abordada en Francia- o el "avis" del Consejo de Estado luxemburgués de 4 de mayo de 1999.

A continuación, desde la perspectiva indicada y siguiendo el orden en que aparecen en el texto internacional, se procede a formular diversas consideraciones derivadas del contraste de determinados preceptos del Estatuto de Roma con la Constitución española, en el que se pueden detectar algunos puntos de eventual fricción o de potencial divergencia interpretativa.

A) Una primera dificultad se suscitaría a partir de los artículos 17 y 20 del Estatuto, que incluyen la expresión más radical del principio de complementariedad de la jurisdicción de la CPI. La complementariedad de la jurisdicción de la CPI respecto de las jurisdiccionales penales nacionales (artículo 1) se traduce en el carácter extraordinario de la intervención de dicho órgano, sólo en defecto del ejercicio debido y efectivo de su jurisdicción por los Estados Partes. Tal complementariedad funciona en realidad de modo distinto en circunstancias ordinarias - en las que vendría a actuar a modo de subsidiariedad- que en circunstancias extraordinarias cuando los órganos nacionales hayan ejercido sus competencias en fraude del Estatuto o de forma puramente aparente -supuestos en que la complementariedad se trocaría en auténtica primacía o preferencia-. Para situar 
el contexto en que el Estatuto preve la actuación de la CPI baste la especificación en el artículo 17.3 de tales circunstancias extraordinarias, que habrá de tener en cuenta para afirmar su competencia, cuando se refiere a que el Estado Parte esté en una situación de "colapso total o sustancial de su administración nacional de justicia" o que carezcan de ella.

En virtud del apartado 1 del artículo 17 (sobre "cuestiones de admisibilidad") se permite a la CPI admitir un asunto: a) cuando éste sea objeto de una investigación o enjuiciamiento en el Estado que tiene jurisdicción sobre él si no está dispuesto a llevar a cabo la investigación o el enjuiciamiento o no puede realmente hacerlo; b) cuando éste haya sido objeto de una investigación o enjuiciamiento por el Estado que tenga jurisdicción sobre él, pese a que haya decidido no incoar la acción penal sobre la persona de que se trate, si considera que la decisión ha obedecido a que no esté dispuesto a llevar a cabo el enjuiciamiento o no pueda realmente hacerlo, y c) cuando la persona de que se trate haya sido enjuiciada por la conducta a que se refiere la denuncia y la Corte no pueda incoar el juicio con arreglo a lo dispuesto en el párrafo 3 del artículo 20. Dicho artículo 20.3 permite que la CPI no se atenga a la cosa juzgada por otro tribunal si estimara que el proceso llevado a cabo obedeciera al propósito de sustraer al acusado de su responsabilidad penal por crímenes de competencia de la Corte o no hubiere sido instruido en forma independiente o imparcial de conformidad con las debidas garantías procesales reconocidas por el derecho internacional o lo hubiere sido de alguna manera que, en las circunstancias del caso, fuere incompatible con la intención de someter a la persona a la acción de la justicia. La competencia de la CPI en tales casos podría ser, ciertamente, impugnada en virtud del artículo 19, pero, en definitiva, la decisión final (la competencia de la competencia) corresponde a la CPI, que puede imponerse sobre las decisiones de las jurisdicciones nacionales.

La función que cumplen los preceptos mencionados es, en definitiva, permitir la transferencia a la CPI de potestades jurisdiccionales que la Constitución reserva en exclusiva a los Juzgados y Tribunales integrantes del Poder Judicial (art. 117.3 CE), por lo que entiende el Consejo de Estado que el mecanismo del artículo $93 \mathrm{CE}$ ampara una cesión tal del ejercicio (por lo demás, complementario, siempre y cuando España no las ejerza realmente por alguna de las razones mencionadas) de las referidas competencias. Toda atribución del ejercicio de competencias derivadas de la Constitución a una organización o institución internacional implica el reconocimiento de una intervención (con desplazamiento total o parcial de los órganos españoles, según los casos) de poderes internacionales o supranacionales en el ejercicio de competencias derivadas de la Constitución. Tratándose de competencias judiciales, resulta inherente a la transferencia de su ejercicio el admitir la existencia de instancias por encima de los órganos jurisdiccionales españoles que resultarán habilitadas para pronunciarse sobre hechos y materias en los que éstos, hasta el presente, tienen la potestad última de decir el derecho.

Cuestión delicada es que con la transferencia del ejercicio de competencias se autorizará a la CPI a valorar (juicio previo al de fondo) si le es oponible la 
cosa juzgada en la instancia nacional o si, por el contrario y ante la ausencia de un pronunciamiento recaído en juicio con las garantías procesales debidas (a cuya observancia se alude reiteradamente en los artículos 17.2 y 20.3.b), puede entrar de nuevo en el enjuiciamiento de los hechos de que se trate. Frente a un entendimiento extremo de esta posibilidad en contradicción con el principio ne bis in idem y con eventual erosión de lo previsto en el artículo 24.1 de la Constitución, hay que observar primeramente que el derecho a la tutela judicial efectiva establecido en el citado precepto constitucional no se constriñe expresamente a la que otorguen los jueces y tribunales españoles sino que puede entenderse abierta a los órganos jurisdiccionales cuya competencia admita España. Además, cabe señalar -como ha dicho el Tribunal Constitucional- que el derecho a la tutela judicial efectiva reconocido en el artículo 24.1 significa ciertamente el respeto de la firmeza de las resoluciones judiciales y de la intangibilidad de las situaciones jurídicas en ellas declaradas pero "sin perjuicio, naturalmente, de su revisión o modificación a través de los cauces extraordinarios legalmente reconocidos" (STC 59/1996). La cesión de competencias judiciales a la CPI habilitaría a ésta para, en las circunstancias y por los cauces establecidos por su "ley" reguladora (debidamente integrada en el ordenamiento español), modificar en su caso las resoluciones de órganos españoles.

B) El artículo 27 del Estatuto de la CPI establece la simprocedencia del cargo oficial" en los siguientes términos:

“1. El presente Estatuto será aplicable por igual a todos sin distinción alguna basada en el cargo oficial. En particular, el cargo oficial de una persona, sea Jefe de Estado o de Gobierno, miembro de un gobierno o parlamento, representante elegido o funcionario de gobierno, en ningún caso la eximirá de responsabilidad penal ni constituirá per se motivo para reducir la pena.

2. Las inmunidades y las normas de procedimiento especiales que conlleve el cargo oficial de una persona, con arreglo al derecho interno o al derecho internacional, no obstarán para que la Corte ejerza su competencia sobre ella".

Este precepto tiene su antecedente inmediato en el artículo 7 del Proyecto de la Comisión de Derecho Internacional de las Naciones Unidas, en cuyo informe rendido a la Asamblea General sobre la labor realizada en su $48 .^{\circ}$ período de sesiones se indica que el sentido último de la inadmisibilidad del cargo oficial como excusa absolutoria es evitar -como ya se hizo en el Estatuto del Tribunal de Nuremberg- la alegación de "actos de Estado", de modo que quienes los ejecuten no sean responsables penalmente sino que estarían protegidos por la doctrina de la soberanía de Estado. "Las palabras incluso si actuó como Jefe de Estado o de Gobierno reafirman la aplicación del principio contenido en el presente artículo a los individuos que... tengan los mayores poderes de decisión".

El tenor del artículo del Estatuto de Roma, más amplio que el del citado precepto, conduce a tratar la posible colisión de éste con diversos artículos constitucionales.

Teniendo en cuenta las prescripciones constitucionales sobre el estatuto jurídico de los parlamentarios, podría apreciarse una inicial contradicción entre el artículo mencionado del Estatuto de la CPI y el artículo 71 de la Constitución. Este último establece la inviolabilidad de los Diputados y Senadores por las opiniones 
manifestadas en el ejercicio de sus funciones, su inmunidad durante el período de su mandato, la prohibición de que sean inculpados o procesados sin la previa autorización de la Cámara respectiva y el privilegio de fuero determinante de la competencia de la Sala de lo Penal del Tribunal Supremo.

La inviolabilidad parlamentaria supone en el Derecho español la total irresponsabilidad jurídica ("privilegio de naturaleza sustantiva" según las SSTC 36/1998 y 243/1988) de que goza el parlamentario por las opiniones expresadas en el ejercicio de sus funciones. Una acepción estricta del ámbito de esta prerrogativa la sitúa en el terreno de la libertad de palabra, sin que cubra propiamente el ejercicio del derecho de voto, que supone algo más pues constituye una manifestación volitiva. Siendo claro que en el uso de la libertad de expresión amparada por la referida inviolabilidad parlamentaria difícilmente podría incurrir el parlamentario en alguno de los crímenes sobre los que se establece la competencia de la CPI, no se ve posibilidad de choque entre tal previsión y lo requerido por el artículo 27.1 del Estatuto más que, quizá, en algún supuesto, como podría ser la instigación directa y pública al genocidio (artículo 25.3.e).

Cuestión distinta y de trascendencia infraconstitucional, aunque con severas posiciones doctrinales en discrepancia, sería la extensión -para muchos sólo especificación- que determinadas normas han efectuado de la citada prerrogativa de forma que proteja expresamente la libertad de voto, así el artículo 21 del Reglamento del Senado e, incluso, los reglamentos de las Asambleas de diversas Comunidades Autónomas. En su caso y en la posición más estricta, la ratificación del Estatuto de la CPI podría comportar la modificación de (o, mejor, la necesidad de modificar) lo previsto en tal sentido por las mencionadas normas.

En cuanto a las inmunidades o prerrogativas de naturaleza formal (conforme a las SSTC 90/1985 y 243/1988) de que gozan los parlamentarios, mientras dure su mandato, de no poder ser detenidos, procesados ni inculpados sin la previa autorización de la Cámara a la que pertenecen, no cabe silenciar la inadmisión de aquéllas por la jurisdicción de la CPI, dados los términos literales del artículos 27.2 de su Estatuto. Como el artículo 93 autoriza a transferir competencias derivadas de la Constitución (según están configuradas por ésta), la competencia que se podría atribuir a la Corte por esta vía sería la misma (no otra distinta) que ejercen los poderes públicos españoles y con sus propios límites, lo cual parece difícilmente compatible con el régimen del Estatuto. Sin embargo, un entendimiento de tales prerrogativas como límite constreñido a las competencias de las autoridades estatales es coherentemente esgrimible en atención al fundamento institucional -y no al carácter personal-, que está en el origen histórico y dogmático de esas prerrogativas, y a su función en la articulación político-constitucional de los poderes del Estado como secuencia sedimentada del principio de ordenación que, dicho de modo simplificado y expresivo, se asocia a la doctrina de la "división de poderes".

No parece, por otra parte, que el privilegio de fuero presente una incompatibilidad irreductible con el precepto convencional de referencia. El Tribunal Constitucional ha conectado la garantía de aforamiento prevista en el artículo 71.3 de la Constitución para Diputados y Senadores con el derecho al Juez ordinario 
predeterminado por la ley del artículo 24.2 del mismo texto (STC 22/1997). Se trata pues, en términos estrictos, de un tema de titularidad y atribución de ejercicio de una potestad jurisdiccional, no de un límite material o formal a su ejercicio. Desde esta perspectiva, la cesión del ejercicio de competencias jurisdiccionales a la CPI, como se viene sosteniendo, es una manifestación de la apertura internacional autorizada por la vía del artículo 93 de la Constitución en tanto que sólo afecta -en los casos, por lo demás, excepcionales previstos en el Estatutoal órgano que la ejerce pero no a los límites constitucionales de su ejercicio.

La referencia del artículo 27 del nuevo Tratado a la inadmisibilidad de normas de procedimiento especiales respecto de determinadas personas en atención a su cargo oficial, aún existiendo tales normas en el ordenamiento español, no incurre en antítesis con la Constitución dado que figuran en disposiciones de rango legal.

Las reflexiones anteriores pueden proyectarse, culminando en lo que proceda la línea argumental iniciada, para el contraste entre el mismo artículo 27 del Estatuto y los artículos 56.3 y 102 de la Constitución.

El artículo 56.3 de la Constitución recoge la inviolabilidad de la persona del Rey y declara que no está sujeta a responsabilidad. Resulta palmario que, pese a la identidad del significante («inviolabilidad") empleado en este artículo y en el 71 , su significado no es unívoco en uno y otro. Si la inviolabilidad parlamentaria se funda en la protección de la libertad de expresión de los parlamentarios (a los que, aun siendo responsables de sus actos, no puede exigírseles responsabilidad por ellos en vía judicial penal, según quiere la Constitución), la del Jefe del Estado se fundamenta en su posición, ajena a toda controversia, dado el carácter debido de sus actos en el modelo constitucional de 1978. Es más, no se puede hablar en este último caso de ausencia absoluta de responsabilidad exigible por unos actos -que sería la consecuencia última de la inviolabilidad parlamentariasino de imputación de la que pueda derivarse de ellos al órgano refrendante (arts. 56.3 y 64.2 de la Constitución). En suma, la irresponsabilidad de quien refrenda y que, por ello, es el que incurría en la eventual "responsabilidad penal individualn a que se refiere el artículo 25 del Estatuto.

La interpretación esbozada, cimentada sobre categorías dogmáticas acuñadas en el Derecho Constitucional comparado por referencia al régimen parlamentario más intenso y, en particular, a la forma política de las Monarquías parlamentarias (caracterización asumida por la Constitución de 1978 en el art. 1.2), no ha de representar una fractura de los propósitos y fines del Estatuto de Roma ni de los términos en que define la competencia de la CPI sino una aplicación plena de aquél con respecto de las variadas concepciones políticas vigentes en los que serán sus Estados Partes, aún entendiendo el Consejo de Estado que sobre este extremo cabrían otras orientaciones interpretativas. En todo caso, naturalmente, no se trataría de operar una limitación de la competencia de la CPI sino una delimitación de su ámbito propio y pleno en su proyección respecto de España. Atribuir al Estatuto, en cambio, un efecto modificativo de principios esenciales en la forma política de los Estados parece sobrepasar el objeto y fin que le son propios. En tal sentido, se constata que en su propio texto existen pasajes que per- 
miten mantener la posición defendida, ya sea en preceptos de alcance general (el art. 21.1.c incluye entre las fuentes del derecho aplicables por la CPI el derecho interno de los Estados que normalmente ejercerían jurisdicción, siempre que esos principios no sean incompatibles con el Estatuto, y a él se remite el art. 31.3), ya sea en artículos específicos (como el 28.1, que insiste reiteradamente, respecto de la responsabilidad de los jefes militares y superiores, en la efectividad de su mando y control).

Finalmente, un último contraste del artículo 27 del Estatuto con la Constitución permite concluir, aplicando la argumentación esbozada respecto del artículo 71.3, que no se observa contradicción de aquel con el artículo 102.1 de la Constitución -en lo que hace al fuero- que no sea superable por la vía del artículo 93 de la Constitución. Y, en cuanto a los requisitos para que pueda acusarse al Presidente y a los miembros del Gobierno por traición o por cualquier delito contra la seguridad del Estado previstos en el artículo 102.2, un entendimiento estricto del artículo 27 del Estatuto de Roma -referido a normas de procedimientos especiales- permitiría aducir que se está ante requisitos previos al procedimiento. Es cierto sin embargo que, en una interpretación quizás más ajustada al espíritu del precepto convencional, tales condiciones podrían incluirse entre las que están vedadas como limitativas de la competencia de la Corte, lo que podría exigir asimismo su revisión constitucional para el caso. Pero, en puridad, el Consejo de Estado entiende que, en los delitos a que se refiere el citado precepto constitucional, pudiera primar su proyección interna sobre su improbable trascendencia internacional, de forma que no tendrían por qué considerarse incluidos entre los crímenes de competencia de la Corte, que protegen bienes jurídicos muy distintos.

C) El artículo 77 del Estatuto de la CPI incluye dentro del catálogo de penas aplicables la de reclusión a perpetuidad, cuando lo justifiquen la extrema gravedad del crimen y las circunstancias personales del condenado. Como quiera que una cosa es la imposición de tal pena privativa de libertad y otra distinta la función que se atribuye a su cumplimiento, sería discutible que dicha previsión per $s e$ entrara en colisión irreductible con el artículo 25.2 de la Constitución. En todo caso, los eventuales reparos en cuanto a su admisibilidad desde el orden constitucional vigente decaen hasta un nivel relativo gracias a diversas modulaciones al respecto dentro del propio Estatuto.

En primer lugar, el artículo 80 establece que "nada de lo dispuesto en la presente parte se entenderá en perjuicio de la aplicación por los Estados de las penas prescritas por su legislación nacional ni de la legislación de los Estados en que no existan las penas prescritas en la presente parte». Aplicando esta última cláusula de salvaguardia España, como Estado de ejecución, no vería afectados los principios constitucionales previstos en el artículo 25.2 que -en su entendimiento más extremo y sin tener en cuenta otros mecanismos de interrupción de la ejecución de las penas- podrían conducir a rechazar penas perpetuas por colisionar con la reeducación y reinserción social de los condenados. Es más, el artículo 103.1.b) del Estatuto admite que; "en el momento de declarar que está dispuesto a recibir condenados, el Estado podrá poner condiciones a reserva de que sean 
aceptadas por la Corte y estén en conformidad con la presente parte" y el mismo artículo, en el párrafo e) de su apartado 3, establece que la Corte, al ejercer su facultad discrecional de efectuar la designación prevista en el 1. tendrá en cuenta "Otros factores relativos a las circunstancias del crimen o del condenado, o a las ejecución eficaz de la pena, según procedan en la designación del Estado de ejecución".

Aunque podría dudarse de que los anteriores preceptos permitieran evitar a todo trance la imposición de penas a perpetuidad a nacionales españoles (especialmente si España no es el Estado de cumplimiento), parece que esta eventualidad $-\mathrm{y}$ su posible fricción con el aludido artículo de la Constitución española encuentra una flexibilización suficiente en la reducción de las penas previstas en el artículo 110 del Estatuto, cuya revisión -que en todo caso deberá plantearse a los 25 años de prisión en caso de cadena perpetua y podrá volverse a suscitardenota una posición de principio tendente a la limitación temporal de las penas (cabe recordar que en diversos ordenamientos la reclusión perpetua coexiste con el beneficio de la libertad condicional, sin colisionar, por tanto, con una ejecución de la pena orientada a la reeducación y reinserción social).

D) El artículo 99.4 del Estatuto de Roma permite determinadas actuaciones del Fiscal en el territorio de los Estados Partes, para el caso de que una solicitud pueda ejecutarse sin necesidad de medidas coercitivas, aún cuando sea sin la presencia de las autoridades del Estado Parte requerido. Las funciones en materia de cooperación y asistencia a que se refiere, enunciadas en los artículos 54.2, 93 y 96 del Estatuto, son competencia en su mayor parte del Poder Judicial conforme a la Constitución, en la medida en que podrían coincidir con funciones judiciales de instrucción. De acuerdo con el parecer del Ministerio de Asuntos Exteriores, se estima que las eventuales excepciones que ellas supongan a la exclusividad del ejercicio de la función judicial prevista por el artículo 117.3 de la Constitución, o bien a la misión constitucional (ex artículo 124) del Ministerio Fiscal de promover la acción de la justicia en defensa de la legalidad, pueden reconducirse por el procedimiento del artículo 93 de la Constitución.

V. Para la eventualidad de una reforma constitucional, por el procedimiento del artículo 167 de la Constitución dado el carácter limitado de lo hipotéticamente controvertible (así, las prerrogativas del art. 71 de la Constitución), no existe un modo único y necesario de llevarla a cabo. La fórmula más directa y simple de articularla sería probablemente la adición de un apartado al propio artículo afectado, de modo que a través de él se verificara su apertura al Estatuto de Roma de la CPI. Junto a la ventaja de la restricción específica del alcance de la revisión constitucional que esta opción presenta se advierte, sin embargo, que no ofrece un cierre completo y definitivo a eventuales interpretaciones discrepantes de las postuladas en relación con los otros preceptos constitucionales anteriormente examinados.

Cabría pensar, alternativamente y siguiendo la pauta de las reformas constitucionales abordadas en Francia y Luxemburgo, en la posibilidad de introducir -a los efectos de reforma pretendidos- una previsión genérica de apertura. La Constitución 
española no exige ningún requisito de tipo material para la formulación de la reforma, como podría ser la identificación de la parte de la Constitución o del artículo o artículos que resultan afectados. Podría así declarar el nuevo precepto que se añada que las disposiciones de la Constitución no constituyen obstáculo para la ratificación por España del Estatuto de Roma de la Corte Penal Internacional, hecho en Roma el 17 de julio de 1998. Incluso, sin necesidad de constitucionalizar expresamente éste y para permitir en el futuro eventuales nuevas aperturas, cabría referirla de modo aún más genérico a que las prescripciones constitucionales no son óbice para el reconocimiento por España de la competencia de órganos jurisdiccionales internacionales, siempre que la atribución de competencias a éstos se verifique por el procedimiento del artículo 93 de la Constitución.

Dado el contenido y alcance de una previsión tal, en tanto que norma que incorporaría un régimen jurídico específico a modo de matización o adición al general previsto en el artículo, podría pensarse en su inserción en una disposición adicional.

Una formulación como la indicada en segundo lugar quizá diluyera la certeza en cuanto al precepto (o preceptos) constitucionales que son afectados, pero hay que tener en cuenta que da mayor flexibilidad a su alcance, siempre con el límite que deriva del hecho de haber empleado el procedimiento del artículo 167 para la reforma constitucional. Asimismo una exposición de motivos suficientemente expresiva garantizaría la interpretación auténtica en el sentido mantenido. Por último, es factor a ponderar que, con una previsión genérica habilitante de la incorporación al ordenamiento español del Estatuto de Roma, no sería cuestionable su integración constitucional.

VI. Finalmente hay que reparar en que existen, por otra parte, en el Estatuto de Roma de la CPI previsiones y prescripciones varias claramente reconducibles a diversos supuestos regulados en el artículo 94.1 de la Constitución. Es innegable el carácter político del nuevo Tratado en tanto que se trata de un texto de trascendencia institucional y efecto estructural para la Comunidad Internacional. Afecta notoriamente a derechos y deberes fundamentales establecidos en el Título I de la Constitución. Implica obligaciones financieras para la Hacienda Pública por el sistema de financiación previsto a partir, entre otras fuentes de ingresos, de cuotas de los Estados Partes. Sin duda supone modificación de preceptos legales vigentes en el ordenamiento español (algunos ya indicados en el apartado anterior) y requerirá medidas legislativas para su ejecución (especialmente normas procesales y, quizás, penales).

En todo caso, la subsunción por tales conceptos del Estatuto de Roma en los párrafos a), c), d) y e) del artículo 94.1 de la Constitución, determinante de la necesidad de autorización de las Cortes Generales con carácter previo a la prestación del consentimiento del Estado para obligarse mediante él, queda absorbida, en cuanto al procedimiento de autorización a seguir, por la más cualificada vía del artículo 93 -de obligada observancia en este caso por las razones antes desarrolladas- que exige la expresión de tal autorización por medio de ley orgánica. 
Y, en mérito de lo expuesto, el Consejo de Estado es de dictamen:

Que la prestación del consentimiento del Estado para obligarse por medio del Estatuto de Roma de la Corte Penal Internacional requiere autorización de las Cortes Generales mediante ley orgánica aprobada al amparo del artículo 93 de la Constitución. 